University of North Florida

UNIVERSITY of

NORTH FLORIDA.

UNF Digital Commons

6-1990

\title{
An Examination of Factors for the Strategic Use of Information Systems in the Healthcare Industry
}

K. Kyu Kim

Jeffrey E. Michelman

University of North Florida, jeff.michelman@unf.edu

Follow this and additional works at: https://digitalcommons.unf.edu/bacc_facpub

Part of the Accounting Commons, and the Finance and Financial Management Commons

\section{Recommended Citation}

Kim, K. Kyu and Michelman, Jeffrey E., "An Examination of Factors for the Strategic Use of Information Systems in the Healthcare Industry" (1990). Accounting and Finance Faculty Publications. 2. https://digitalcommons.unf.edu/bacc_facpub/2

This Article is brought to you for free and open access by the Department of Accounting and Finance at UNF Digital Commons. It has been accepted for inclusion in Accounting and Finance Faculty Publications by an authorized administrator of UNF Digital Commons. For more information, please contact Digital Projects. (c) 6-1990 All Rights Reserved

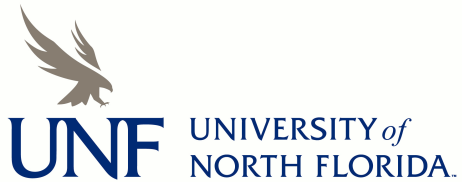




\section{Executive Overview}

The use of an information system as a competitive weapon is, of course, a topic of considerable interest these days. Usually the interest is centered on the for-profit sector, where notions of combat in the marketplace are not at all foreign. Competition among organizations in the not-for-profit sector, such as hospitals and universities, is usually thought to be more muted and genteel. As organizations in the non-profit sector fight for survival in an increasingly harsh environment, however, there is no reason for them to forego potential strategic advantages through the use of information technology.

Based on a series of four case studies, this article examines the conditions under which a hospital might expect to gain competitive advantages. The special culture of a hospital, in which physicians hold a great deal of power relative to the hospital administration, must certainly be taken into account. The authors also assert that strategic systems must generally integrate the more traditional transaction processing and information reporting systems. When done right, though, a healthcare organization can expect to achieve competitive advantages through its information system.

The article has obvious relevance for those involved in healthcare institutions. It also has broader implications, however, because the issues discussed-e.g., the importance of taking account of organizational culture and the need for a strategic system to penetrate into operational activities-have general applicability. 


\section{An Examination of Factors for the Strategic Use of Information Systems in the Healthcare Industry ${ }^{1}$}

\author{
By: K. Kyu Kim \\ Accounting and MIS \\ In-ha University \\ Inchon 160, Korea
}

Jeffrey E. Michelman
College of Business Administration
University of North Florida
4567 St. Johns Bluff Road
Jacksonville, Florida 32216-6699

\section{Abstract}

The potential use of information systems technology (IST) as a competitive weapon has been of enormous interest to many academic scholars and practitioners. However, the importance of identifying factors that organizations must deal with in the process of achieving IST competitive advantages has received inadequate research attention. This article attempts to identify these important factors for the strategic use of IST by examining the multifaceted role of IST in the healthcare context. Three propositions are developed from (1) re-examining a variety of successful IST applications both within and outside healthcare organizations, (2) re-applying the integration concept from the literature, and (3) examining field experiences in the healthcare industry. These propositions should serve as a basis for future empirical investigations into IST strategic applications.

Keywords: Strategic information systems, hospital information systems, integrated systems, political boundaries

ACM Categories: H.4.0, H.4.2, K.6, K.6.0

\footnotetext{
${ }^{1}$ Earlier versions of this paper were presented at the April 1988 ORSATIMS meeting and at the 1988 Academy of Management National Meeting. Any errors or omissions remain the fault of the authors.
}

\section{Introduction}

Organizations have increasingly been turning their attention to opportunities for achieving competitive advantages through information systems technology (IST). The new phenomena can be attributed to several factors such as the changing economic conditions, which include long-term high inflation, high interest rates, and low real growth (Benjamin, et al., 1984); structural changes in the economy caused by global competition (Ives and Learmonth, 1984); and new information technology economics such as telecommunications cost performance and cost performance of circuitry and mass storage (Benjamin and Scott Morton, 1988).

Opportunities exist for healthcare organizations in particular to gain an edge over their competitors through the use of IST. The need to use hospital information systems (HIS) as a competitive weapon has been further heightened by the competitive pressures that pervade the healthcare industry. ${ }^{2}$ The change from cost-based reimbursement to fixed fee payment structures has forced the healthcare industry to put more emphasis than ever before on the efficiency of the patient care delivery process (Havinghurst, 1986; Reynolds, 1986). Under the cost-based reimbursement type of incentive structure that characterized the industry prior to the early 1980 s, there was no need for the strategic use of HIS because "a bed built became a bed filled" (Roemer and Shain, 1959). ${ }^{3}$

As the contemporary environment takes shape and hospitals became healthcare organizations through vertical integration (Conrad, et al., 1988), the need to develop institution-wide information systems for decision making has become paramount. The increasingly competitive pressures

\footnotetext{
2 Altman and Rodwin (1988) describe this as regulated competition, which has fostered the need for healthcare providers to market new products that differ greatly from the traditional inpatient acute care services. The intensity of this competitive influence was depicted in a recent Wall Street Journal headline that stated: "Hospitals that Need Patients Pay Bounties for Doctors Referrals" (Boganich, W. and Waldholz, M., February 27, 1989).

${ }^{3}$ In the past, hospitals were reimbursed on a "reasonable cost" basis. This payment structure facilitated both the rapid construction of excess beds and efforts by hospitals to keep these beds occupied. The payment mechanisms that characterize the contemporary environment reward hospitals for efficiency (Eastaugh, 1987).
} 
have fostered new incentives for the development of organizational strategies that reach far beyond the traditional mission statement that hospitals have long relied upon (Enthoven, 1988; Harrell and Fors, 1986). As hospitals attempt to develop innovative programs and make strategic decisions about their future direction, the quality and availability of information for decision-making has continued to gain greater importance. The rapidly changing environmental influences that have accompanied the abundant introduction of assorted IST make the healthcare sector an important arena for examining the strategic use of information systems.

This article has three primary purposes. First, it attempts to identify factors that healthcare organizations must deal with before they can achieve competitive advantages through the use of IST. Second, in order to expedite empirical investigations into the strategic use of HIS, propositions are developed from a re-examination of successful IST applications, a re-application of the integration concept in the literature, and field experiences in the healthcare industry. Third, a model is developed that adapts the works of Porter $(1979 ; 1980 ; 1985)$ by examining the role of IST in the competitive healthcare arena. Further, hospital examples that support the plausibility of the propositions are provided from field experiences.

\section{IST as a Competitive Weapon: The Literature}

The potential use of IST as a competitive weapon has been of enormous interest to many academic scholars and practitioners since Porter's (1979) work on industry analysis and the formulation of competitive strategies appeared. Bakos and Treacy (1986) report that more than 200 papers were published in the area of IST as a competitive weapon during the $1980 \mathrm{~s}$. This literature shares two common characteristics: (1) proliferation of "frameworks" for identifying and categorizing opportunities for the strategic use of IST (Bakos and Treacy, 1986; Ives and Learmonth, 1984) and (2) descriptions of success stories using IST as a competitive weapon (Treacy, 1986).

In the first characteristic, as is typical of a new field of study, this literature abounds with a number of descriptive frameworks for identifying and categorizing opportunities (Bakos and Treacy,
1986). For example, Porter (1979) identifies five major competitive forces that firms wishing to gain competitive advantages should consider: (1) the threat of new entrants, (2) the bargaining power of customers, (3) the bargaining power of suppliers, (4) the threat of substitute products or services, and (5) the maneuvering among current contestants. With this understanding, IST can be used to implement one of the three generic competitive strategies as defined by Porter (overall cost leadership, product differentiation, and special market focus).

Another example can be found in the customer resource life cycle, drawn from the work of Burnstine (1980) and modified by Ives and Learmonth (1984). Ives and Learmonth maintain that a customer's resource acquisition activities consist of four major phases-requirements, acquisition, stewardship, and retirement. They also maintain that possibilities for using IST to enhance customer service exist within each stage of the customer's resource life cycle.

Cash and Konsynski (1985) examine the various forms of inter-organizational systems (IOS) and develop the three-level classification scheme: (1) information entry and receipt, (2) software development and maintenance, and (3) network and processing management. At the first level is the firm that merely acts as an information entryreceipt node. Companies participating at level 2 develop and maintain software used by other IOS participants. The level 3 participant serves as a utility and usually owns or manages all the network facilities as well as the computer processing resources. As the level of involvement increases, responsibility, cost commitment, and organizational and technical complexity also increase. The classification scheme serves as a useful tool for understanding the multitude of IOSs. Many related frameworks have been proposed by researchers such as Bakos and Treacy (1986), Barrett and Konsynski (1982), Benjamin, et al. (1984), Johnston and Vitale (1988), and McFarlan and McKenney (1983), among others.

The existence of various frameworks is useful because managers may find opportunities for the strategic use of IST by using these frameworks as a guide. However, there is still a marked lack of understanding of specific factors that organizations must deal with in the process of achieving competitive advantages through the use of their IST. Also, the processes that allow a smooth in- 
tegration of technology into organizations need scrutiny. The extant frameworks will be useful only after organizations successfully deal with these important factors and thereby make their information systems ready to be used as a competitive weapon.

The second chacteristic of the existing literature is that descriptions of successful IST applications to strategic areas have appeared as supporting evidence for the proposed frameworks. The now classic examples of IST as a competitive weapon include the computerized reservation systems of American and United Airlines-Sabre and Apollo, respectively-the order entry system of American Hospital Supply, the distribution system of McKesson, and the Cash Management Account ${ }^{\circledR}$ of Merrill Lynch (Barrett, 1986-87).

By using real-life examples, useful insight into the complexities of managing IST to gain competitive advantages is provided. Although researchers frequently attempt to generalize their findings by developing frameworks on the basis of specific anecdotes, such generalizations are often assailed on the grounds that many site-specific factors may contribute to the success of each case (Cale and Curley, 1987). Thus, more systematic investigations should be undertaken.

In short, the extant literature attempts to provide useful frameworks-supported by some anecdotes of successful IST applications to competitive advantages - that may help managers identify potential areas where they can use their IST as a competitive weapon. However, the issue of identification of important factors that organizations must deal with in the process of achieving IST competitive advantages has received inadequate research attention. This article addresses these factors in the context of the health care industry. In order to move beyond descriptive frameworks and toward explanatory models of the underlying phenomena (Bakos and Treacy, 1986), more systematic investigations looking into critical factors for the strategic use of IST are clearly called for.

\section{Important Factors for the Strategic Use of IST}

Based on a re-examination of successful IST applications that have appeared in the literature, this section identifies important factors that healthcare organizations should consider in the process of achieving competitive advantages through the use of IST. Propositions are then presented to encourage empirical research that examines the effect of these factors. The overall framework of the following discussion is presented in Figure 1.

The framework in Figure 1 illustrates that many of the successful IST applications had their origins not in sophisticated decision support systems (DSS), but in already existing transaction processing systems (TPS) or information reporting systems (IRS). As the figure shows, three factors influence the development of HIS as a competitive weapon. Factor 1 involves overcoming political issues to achieve integration. Political barriers become significant issues as isolated systems that operate independently throughout the organization are brought together. In particular, the conflict between the inherent values of clinicians and administrators is a well-known problem in the healthcare context (Malvey, 1981; Starr, 1982). The process of negotiation between the two primary constituencies-administrators and physicians-involved in healthcare decision making is inherent in this factor.

Factor 2 involves an organization's attempt to integrate independent TPS and IRS. The integration leads to significant structural change in processes, functions, and organizations. As these systems are developed, integration of independent TPS becomes important to IST success (Benjamin and Scott Morton, 1988). Factor 3 depicts the importance of strategic use. Strategic application and use of IST should take place after political barriers between clinicians and administrators have been mitigated and integration has occurred. Similar problems have also been observed in other industries such as the conflict between manufacturing and engineering in integrated CAD/CAM (Benjamin, et al., 1984; Benjamin and Scott Morton, 1988). Only after organizations successfully achieve the desired level of integration, and thereby make their IST ready to be used as a strategic weapon, can they take advantage of the existing frameworks. Although the sequencing of the three factors may vary, the discussion that follows illustrates the importance of the sequential nature of these relationships.

As products of the factors identified in Figure 1, three propositions are presented and then discussed specifically in the next three sections. Case examples are also presented to empirical- 


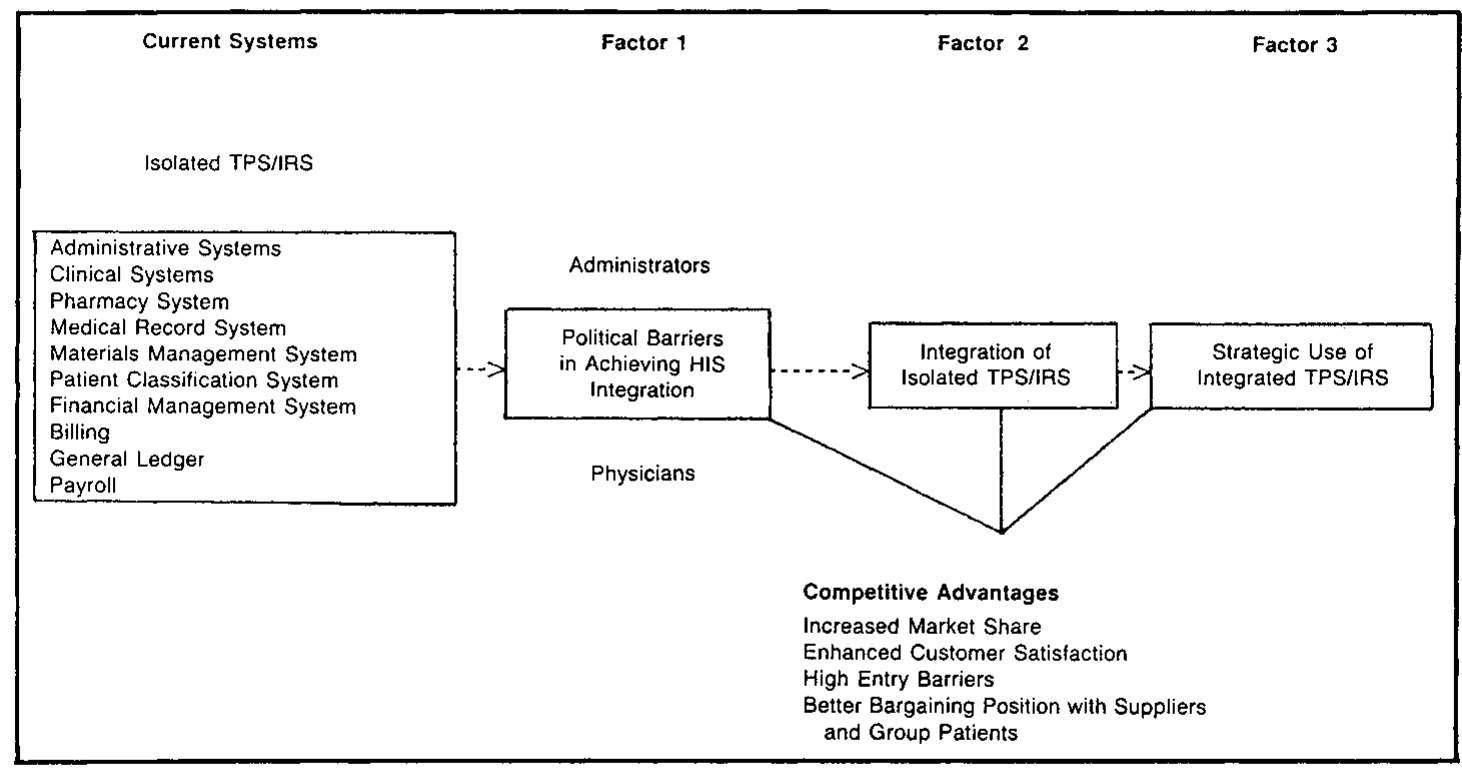

Figure 1. Important Factors in the Development of Hospital Information

\section{Systems as a Competitive Weapon}

ly enhance the theoretical development of these propositions.

\section{Political barriers in achieving HIS integration}

Integration of the existing isolated systems may not be an easy task because it cuts across political boundaries (Malvey, 1981; Markus and Bjorn-Andersen, 1987). The integration may lead to significant organizational changes in work-flow, communication patterns, reporting relationships, and internal control processes (Cash and Konsynski, 1985). Further, the integrated system may change the balance of power among units within the organization.

In the healthcare industry, the political barrier between administrators and physicians is particularly important because of the autonomous role of physicians. It is only the physician who has the right to admit patients to the hospital and to choose and take responsibility for their modes of treatment (Friedson, 1985). Furthermore, they have direct access to the policy-making governing board, rather than having to go through the chief executive officer. Thus, physicians are in a strong economic bargaining position in the hospital, and the resulting political barrier may be much larger in the healthcare setting than in other industries (Malvey, 1981). Understanding the political complexities of the integrated system is, therefore, an important factor for the strategic use of HIS.

In addressing political issues in the healthcare setting, Malvey (1981) argues that the development and use of integrated HIS is troubled from the outset, particularly by the conflict between the inherent values of clinicians and administrators. The changes made by hospitals in adjusting to the myriad of environmental influences in the 1980 s have been accompanied by increased tension between administrators and physicians (Starr, 1982). As management attempts to usurp physicians' power and integrate them into the organizational decision-making process, physicians have adamantly maintained that much of the information they collect is proprietary and therefore unavailable for inclusion in the development of institution-wide information systems (McFarlan and McKenney, 1983).

Further, the development of IST in the contemporary hospital environment poses a direct threat to the physician's gatekeeper role. ${ }^{4}$ Information technology is a resource many people value, and

\footnotetext{
4 The term gatekeeper is used to define the physician's role whereby he/she is the one who determines the patient's eligibility for services and intensity of services as well as the patient's ability to leave the system without incurring financial penalties (Friedson, 1985; Starr, 1982; Stone, 1979).
} 
it seems likely that the gatekeepers of IST would be able to extract rewards from those individuals who depend on it (Pettigrew, 1972). Given the high involvement of MIS departments in an organization's work flow and dependence on computing operations, the theory of strategic contingencies suggests that MIS departments are likely to be powerful players in organizational politics (Markus and Bjørn-Anderson, 1987). Thus, the physician and information specialist may become locked in a struggle for control of the organization's future.

Although it appears that physicians have tempered their beliefs in recent years as a result of the changing economic realities of healthcare delivery, a considerable amount of goal conflict continues to persist in many healthcare organizations. As physicians attempt to understand the changing environment, many of them see information systems as "control systems" whose sole purpose is to monitor and report on their behavior (McFarlan and McKenney, 1983). This perception by physicians is contrary to Mintzberg's (1979) depiction of the professional bureaucracy. "Control over his own work means that the professional works relatively independently of his colleagues, but closely with the clients he serves" (p. 349). Thus, a dialogue should be established between physicians and administrators that focuses on the differences between the sharing of information (i.e., coordination) and the use of information as a control device. An example of the potential for information systems to become a tool for reducing the political barrier between administrators and physicians is illustrated in the following case example.

\section{Case 1}

This hospital is a 600 -bed tertiary care center located in a rural setting in the East and is directly linked with a 400-physician multi-specialty clinic. In 1983 the clinic began a strategy of purchasing smaller physician practices around the state as a means of guaranteeing the strength of the referral network and improving the hospital's occupancy rate, which had fallen below 75 percent. Because the hospital is not located near an urban area, the strength of the referral network is critical to organizational success. The physicians in each of these "outpost" clinics become full members of the clinic and maintain full admitting privileges at the hospital. The growth of this strategy has forced the organization to begin to develop an integrated HIS. Currently, the "outpost" physicians are linked by computer to the main hospital/clinic, but can only process minor administrative details such as patient scheduling in the main clinic. The hospital has begun to put medical records on computer as it begins to integrate different types of patient information, but is somewhat constrained by the cost of this process and the available hardware to support this activity. The information needs of this rapidly growing organization as well as the pivotal role of the medical staff in this particular setting present great potential for both the strategic use of the integrated HIS and the reduction of the political barrier. This IST application offers great potential for reduction of the political barrier because the resulting system will attempt to integrate the information for decision making that is critical for physicians who are geographically separated from the hospital/clinic. Further, the communication linkage will allow the organization to use information more strategically as a means to compete with other hospitals that continue to rely on traditional physician affiliations rather than this concept of employing physicians in distant locations.

One administrator suggested the importance of the political process by stating, "There isn't a decision in this organization that is made without the support of the medical staff. The information integration and marketing concepts have a chance to work here only if the medical staff can see how it will help them to deliver better patient care. There will be some reluctance to using computerized medical records, but when the physicians see the benefits it will work. In this environment, we have to be competitive."

The importance of the medical staff in the development and application of the HIS is proposed as follows:

Proposition 1: For the integration of HIS to be successful, the conflict between physicians and administrators is an important factor that a hospital must effectively deal with.

The use of this case is important because it suggests that an information system application is plausible for reducing the political barrier between administrators and physicians. The system serves as a starting point for IST integration. 


\section{Integration of isolated TPS/IRS}

Integration of isolated TPS/IRS has been suggested in the management information systems (MIS) literature as a critical factor for MIS success (Davis and Olson, 1985; Martin, 1983). Among others, Benjamin and Scott Morton (1988) list four different forms of integration: integration of multiple classes of transaction data, integration of multiple forms of data representation, integration of knowledge, and integration of group communications. Different forms of integration realized through improved communication and larger, more complete databases are often the bases for deriving strategic advantages (Benjamin and Scott Morton, 1988).

Empirical evidence in support of the importance of integration can be found in successful applications of IST to strategic opportunities. For example, the Merrill Lynch Cash Management Account ${ }^{\circledR}$ (CMA) has shattered the traditional boundaries between the banking and securities industries because it is a combination of various financial services all rolled into one product. It would not have been feasible to implement the CMA without integrating the charge card system, the insured savings account system, the money market account system, and the brokerage service system into an integrated information system. In other words, the integration of multiple transaction processing systems makes it possible for users to access very large and rich databases. Another example can be found by examining the American Airlines reservation system, Sabre. Sabre, one of the most widely known examples of the strategic use of IST, is an integrated TPS/IRS covering various airline reservation systems. Sabre has continually expanded, offering travel agents and corporate customers more integrated services that cover theater tickets, limousines, insurance, and a host of other travel-related services (Dock and Wetherbe, 1988). As a result, the airlines that initially developed online reservation systems shifted the balance of competition in their favor. In these cases, integration of the firms' services was accompanied by integration of the supporting IST (Keen, 1981).

In the meantime, the current state of hospital information systems (HIS) is far from being the integrated system that has a full range of functionality across all application areas. Healthcare executives are becoming increasingly frustrated with the overwhelming proliferation of isolated application systems and the independent departmental purchases of microcomputers throughout their organizations (Lemon and Crudele, 1987). This frustration intensifies when their personnel gather data from various systems and attempt to turn the data into information that is useful for a number of end-user information needs in the financial, administrative, and patient care areas, as well as changes in government regulation and competitive forces. As a result, users in healthcare organizations have become accustomed to hearing, "You can't get there from here"; or "Yes we have the information in the organization but we cannot access it on this system"; or "I can get it for you but that would require me to download to hard copy and then manually reinput the data." 5

The lack of integration among systems in the healthcare organizations is partly a result of the way information systems management and technology have evolved in the healthcare industry (Lemon and Meier, 1987). Historically, most suppliers of HIS in the marketplace have been small vendors who have gained a competitive position in the market by selling only one type of application or system. With vendors providing limited offerings, hospital departments had little choice but to concentrate on meeting their own needs without regard to integrating other systems (Lemon and Crudele, 1987). As a result, the typical hospital today has from three to six different system configurations with very limited integration (Hoffman, 1986; Lemon and Crudele, 1987).

Although the development of an integrated HIS is the desired goal of many hospitals today, very few hospitals have reached this stage. The integrated system with a full range of functionality across all application areas is still in the very early development stages. ${ }^{6}$ One attempt to use an information system to link different parts of the organization and integrate different databases is illustrated in the following case:

\footnotetext{
5 This comment is reflective of descriptions of the state-of-theart of HIS by the CIOs of two major teaching hospitals.

6 The integration of HIS is consistent with what Cook, et al (1983) describe as an effective managerial level response to the influence of regulation on hospital decison making. Further, integration of the HIS becomes an important foundation on which to base the integration of the hospital structure (Conrad, et al., 1988).
} 


\section{Case 2}

This organization is a 500-bed teaching hospital located in the Midwest. The hospital recently purchased an organization-wide cost accounting/ information system. Prior to this decision, the hospital began a six year process of trying to integrate different aspects of their information systems that were fragmented throughout the organization. The process began with the development of online patient registration in 1982. During this period, modules were integrated together one by one and system interfaces were acquired. The major interface that remained was the ability to easily merge clinical and financial information across application areas. This activity was originated by the hospital's fiscal affairs staff. The system was purchased primarily because the market in which the hospital operates is very competitive, due in large part to a very high percentage of HMO enrollees in the local community. In this institution, cost containment is clearly an important issue, primarily because of competitive pressures. The organization is attempting to more accurately price their services in the marketplace and decide whether to drop some services and add new ones. This organization is depicted with a strong political barrier between physicians and administrators to the extent that physicians were not actively consulted in the system evaluation and selection processes.

The director of information systems for the hospital offered his insight about the whole process when he stated, "Even though we will have the system in place in the near future, strategic information is still not our goal, it is only a byproduct. We need to continue to bring data together and make the databases more user friendly. Although the medical staff is not completely behind us at this point, this is not surprising; tiney are interested in research. We need to improve communications with the medical staff, and this will help to make the system more useable. At that point we can worry more about the strategic applications."

This case is therefore indicative of the need to first combine existing TPS/IRS before embarking upon strategic applications. Further, the almost eight-year process of system implementation suggested the need for a systems application plan that builds upon the integration process. Although the medical staff was notified about IST decisions and the schedule for implementation, many members of the medical staff still view IST as another way for the administration to both monitor them and control their behavior. In this organization, development of the information system was viewed by administrators as a critical issue in making the organization more competitive. Unfortunately, this strategy has led to a strengthening of the political barrier in the short run as physicians await IST benefits.

This case lends support to the argument that the sequential adaptation of HIS factors helps to build a foundation for eventual system success. In this process, the foundation of TPS/IRS interrelationships throughout the organization helps to form this base. The development of these linkages has been important for system development in the more recent phase. The importance of integrating the isolated TPS/IRS into a strategic HIS application is proposed as follows:

\section{Proposition 2: Integration of isolated TPS/IRS throughout the organization is an important factor in the strategic use of healthcare infor- mation systems.}

Case 2 offers important insight into the development of this proposition, because unlike Case 1, this hospital has begun to integrate their many databases in both form and substance. The size and type of organization as well as the competitive nature of its marketplace are contributing factors in the orientation behind the strategic development of information technology in this organization. Case 2 is particularly important because it illustrates how one hospital has taken existing TPS and attempted to integrate them through the acquisition of a focal system. Yet it should be pointed out that this process took place in large part around the political barrier, and hence, the ability to use the system strategically is still uncertain.

\section{Strategic use of integrated TPS/IRS}

In the last few years, much emphasis has been put on DSS, which supports the process of making decisions (Davis and Olson, 1985). Further, the phrase, "strategic use of IST," which has been used to describe the IST success in achieving advantages over competitors (e.g., see Bakos and Treacy (1986), Benjamin, et al. (1984), Senn (1987)) carries the implicit connotation that firms might have achieved competitive advantages by 
receiving strategic information from their DSS to support long-range strategic planning. However, a strategy is the way in which an organization endeavors to differentiate itself from its competitors, using its relative corporate strengths to better meet customer needs (Ohmae, 1982). A system or application is strategic if it changes the way a firm operates with competitive forces in the environment (Senn, 1987). Thus, it is conceivable that simple TPS or IRS can change the way a firm competes if the firm applies its TPS/IRS to capture strategic opportunities.

The distinction between DSS and TPS/IRS has significant implications for practicing managers because DSS is fundamentally different from TPS/IRS in many aspects; system development procedures (iterative/adaptive vs. system development life cycle), system contents (decision focus vs. data focus), system management (decision-making support vs. routine operational activities), etc.

A close examination of the successful applications frequently cited in the literature reveals that those firms that successfully gained competitive advantages did not accomplish this through sophisticated decision support systems (DSS), but rather through the application of their TPS/ IRS to areas that cope with competitive forces. For example, American Hospital Supply (AHS) developed a transaction processing system, i.e., an order-entry distribution system, that directly links the majority of its customers to AHS computers.

As well as providing the customer with direct access to the AHS order-distribution process, the system allows customers to perform functions, such as inventory control, for themselves... [The system] simplifies ordering processes, reduces costs for both AHS and the customer, and allows AHS to develop and manage pricing incentives to the customer across all product lines. As a result, customer loyalty is high and AHS' market share has been increasing (Benjamin, et al. 1984, p. 5).

McKesson's order-entry distribution system, called Economost, is similar in nature to the AHS system, which automatically takes orders from customers, processes them at a data center and dispatches the orders to McKesson's 50 warehouses. Another example can be found in the Cash Management Account ${ }^{\circledR}$ (CMA) of Merrill
Lynch \& Co. The CMA is a combination of charge card, money market account, insured savings account, and brokerage service, all of which are examples of TPS/IRS. As a result of major regulatory changes in the banking industry, the CMA became the most significant financial product in many years. The introduction of integrated financial services by brokerage firms changed financial institutions permanently and at the same time immediately propelled Merrill Lynch \& Co. into a leadership position in an industry they had been unable to enter (Senn, 1987).

The above applications indicate that those firms who gained competitive advantages did so through the application of their TPS/IRS.

\section{Case 3}

This organization is a 900-bed teaching hospital located in a major metropolitan area in the South, which has been characterized as very competitive. During the late 1970 s and early 1980 s, hospital admissions continued to decline. In 1987, the organization developed an integrated system linking the clinical faculty and community physicians. The hospital loaned IBM PC compatibles with a hard drive, modem, and printer to selected physicians located around the state. The system contains a menu of services that the hospital offers, plus information on faculty credentials and specialty areas, continuing education, and clinical trials. In addition, the community physicians can communicate with both the hospital and the faculty through the use of electronic mail. The system was develped by using a TPS/IRS to build an application-initiated by the marketing department-to make the hospital more competitive.

This system offers great potential for the development of a network throughout the state that would allow community physicians to check the conditions of patients they have referred elsewhere and obtain interactive consultation that can later be documented. This system was initiated as a means to both address the issue of competition in the marketplace-by increasing patient referrals from community physicians-and improve the quality of information for medical decison making. This system was feasible in large part because the physicians (on the clinical faculty) were actively involved in its development and cooperated by providing and updating the necessary data. Further, the system was accepted bv 
the medical staff because of their involvement, and hence, the political barrier was reduced as the organization began to improve relationships with outlying physicians and contemplated integrating other types of information systems together.

The director of marketing offered interesting insight into the effect of the system development on hospital decision making by stating, "The administration was pretty leery about supporting another program that the medical staff wanted to spend money on, but the acceptance of the system and the publicity that it has received has helped to reduce the barrier between the administration and the medical staff."

As a result, both the marketing orientation and physician cooperation in this organization allowed development to start with Factor 2 and then progress to Factor 3 (see Figure 1).

The importance of understanding the role of TPS/IRS in achieving a competitive advantage is proposed as follows:

Proposition 3: Healthcare organizations can achieve competitive advantages through the successful application of TPS/IRS to strategic areas.

This proposition represents the product of HIS success. It is developed in order to help understand why Propositions 1 and 2 are important. Further, Proposition 3 is a fruitful area for drawing upon the experiences of other industries as healthcare applications remain in their infancy.

\section{The Application of HIS to Strategic Initiatives}

This section attempts to illustrate additional possibilities for the propositions discussed above by showing how hospitals can achieve competitive advantages through the use of integrated TPS/IRS. Since a strategy is the way in which an organization copes with competitive forces, the identification of competitive forces in the heathcare industry should precede the discussion of the strategic application of integrated TPS/IRS. Porter's (1979) framework is used to identify these competitive forces and to examine the application of the integrated HIS.

\section{Competitive forces in the healthcare industry}

Porter (1979) identifies five competitive forces that the nature and degree of competition in an industry hinge upon: suppliers, customers, threat of new entrants, substitute products or services, and competition among current contestants. Applying Porter's framework to the healthcare industry, a model that depicts these relationships is developed. In this model, presented in Figure 2 , five competitive forces are identified.

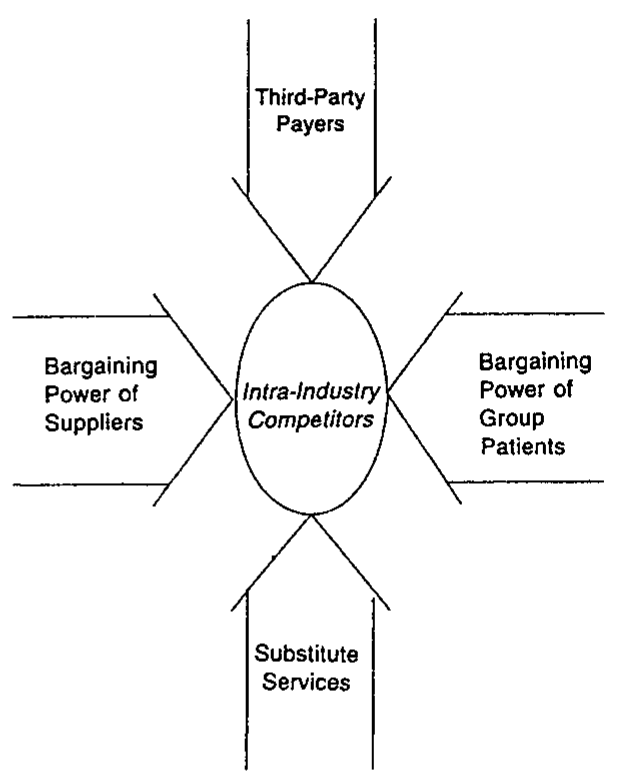

Figure 2. Competitive Forces in the Healthcare Industry

The five competitive forces in the healthcare industry are the bargaining power of group patients, the bargaining power of suppliers, the threat of substitute services for hospital medical care, third party payers, and intra-industry competitors such as other hospitals and community physicians.

In the healthcare industry, a patient group such as a preferred provider organization (PPO) ${ }^{7}$ can exert bargaining power on hospitals by forcing down prices, demanding higher quality or more service, and playing competitors against each other-all at the expense of the hospital's finan-

\footnotetext{
${ }^{7}$ A PPO is usually a healthcare purchaser, such as a union or large organization, who negotiates with a hosoital and medical staff for a lower price of services.
} 
cial viability. Material suppliers such as American Hospital Supply (AHS) and McKesson can exercise bargaining power over hospitals by raising prices or reducing the quality of purchased goods and services. Powerful suppliers can thereby squeeze profitabilty out of a hospital unable to recover cost increases in its own prices due to the changing power of healthcare purchasers (Havinghurst, 1986).

Hospitals increasingly find themselves in competition with substitute services and regulation (Shortell, et al., 1985; Kimberly and Zajac, 1985). Because government agencies often place ceilings on prices that a hospital can charge, substitute services such as nursing homes and the visiting nurses association's (VNA) home care program limit the potential of a hospital. A more recent competitive phenomenon has been the introduction of for-profit surgicenters (Kaluzny, et al., 1987; Shortell, 1988), which allow physicians the opportunity to offer services at a lower cost. The lower cost structure results because the surgicenter does not have to subsidize the costly and complex procedures that take place in the hospital setting.

Unless it can upgrade the quality of the service or differentiate it somehow, the hospital will continue to show decreases in its occupancy level. It is manifest that the more attractive the priceperformance trade-off offered by substitute services, the firmer the lid placed on the industry's profit potential (Porter, 1979). IST can be used as a means for mediating the conflicting demands of regulation and competition.

Third-party payers such as Medicare, Medicaid, Blue Cross, and other private insurers can significantly influence the hospital's financial situation by enforcing a uniform rate per episode (e.g., diagnosis-related groups), by putting a cost ceiling per service, or by simply delaying payments (Cook, et al., 1983; Eastaugh, 1987). Intraindustry competitors such as other hospitals, community physicians, ${ }^{8}$ and heaith maintenance organizations (HMOs) ${ }^{9}$ can take the familiar form of maneuvering for position: using tactics like price competition, new service introduction, and advertisement.

\footnotetext{
${ }^{8}$ Although physicians play a pivotal role in healthcare delivery within the hospital, they have begun to play an active role in opening their own outpatient surgery and treatment facilities.

${ }^{9}$ An HMO is an organization that negotiates a fixed price with the hospital and physician on a per-capita basis.
}

\section{Competitive advantages through the use of integrated TPS/IRS}

Having identified the competitive forces in the healthcare industry, this section examines how an integrated HIS can be used to cope with these competitive forces. Among others, the most dramatic and potentially powerful use of IST is interorganizational systems (IOS) that transcend company boundaries (Cash and Konsynski, 1985; Johnston and Vitale, 1988). The potential impacts of an IOS on inter-organizational relationships include the change in the balance of power beween buyers and suppliers, exit and entry barriers to the industry, and the shift in the competitive positions of intra-industry competitors. Thus, this section utilizes an illustration of IOS that involves an integrated TPS/IRS as a component part. This case is adapted from an information systems plan for a university hospital. The university hospital is in the early design stage of integrating its HIS.

\section{Case 4}

This case involves the systems plan of a 350-bed teaching hospital in the East; the hospital currently has an occupancy rate of about 85 percent. The hospital is particularly interested in IST development as it will be increasing its capacity to approximately 500 beds sometime during 1990. The current system has two subsystems: centralized application systems and individual departmental systems. Centralized application systems consist of a patient database (e.g., medical records, patient accounting, clinic visit information, etc.) and a hospital operation database (e.g., third-party payer information, referring physicians, payroll/personnel information, etc.). Departmental subsystems include radiology, pharmacy, pathology, materials management, laboratory medicine, and clinical care systems. In order to maintain flexibility of individual departmental operations, each department is allowed to operate its own system. However, it is required that each departmental system interface with centralized application systems to achieve the integrity of the complete system. In other words, subsystems should be able to exchange information with each other without making any significant modifications such as writing major programs, re-inputting large volumes of data, or down-loading large amounts of information.

The schematic diagram of the integrated HIS is presented in Figure 3. 


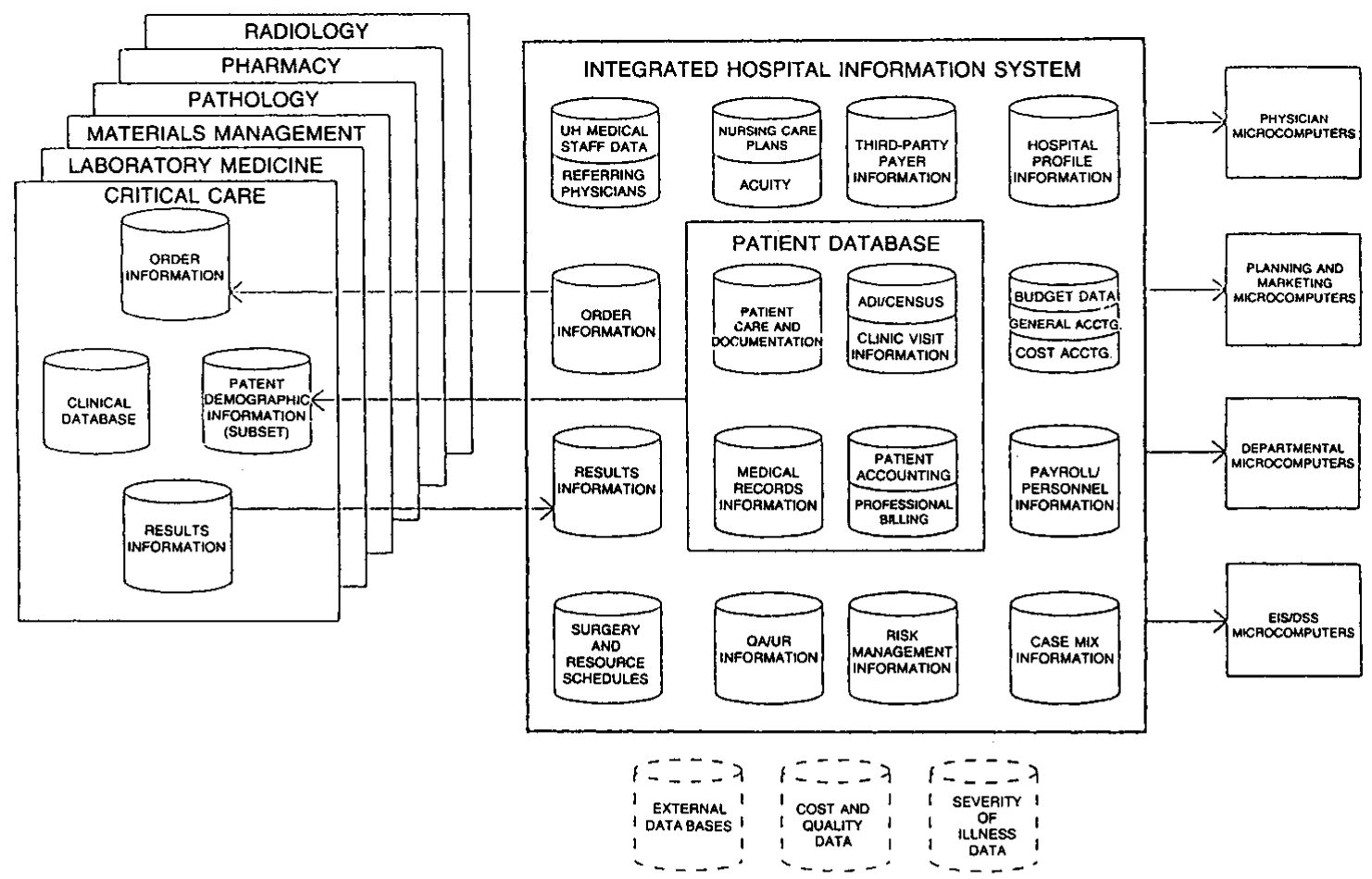

Figure 3. An Integrated Hospital Information System

While the system described above is a typical, but integrated, TPS/IRS, the system can be effectively used to cope with competitive forces in the healthcare industry. For example, the system could link community physicians' computers to the hospital's computers. If community physicians do not have their own computers, the hospital can provide them with its terminals as the hospital did in Case 3. Using this network or the terminals provided by the hospital, the community physicians can have access to the information that resides in the integrated HIS. For example, the community physicians can directly admit their patients from their offices by checking the avail.ability of beds, lab schedules, and physicians in the hospital. The community physicians might also receive the laboratory test results faster, which leads to more timely diagnoses and better patient care. These transactions become feasible only through the integration of administrative systems (e.g., admission/discharge system and billing system) and clinical systems (e.g., laboratory system, physician schedule system, and medical record system). As a result, if community physicians refer more patients to the hospital, the hospital's market share will increase. As multi-institutional hospitals become more commonplace, this application can be pivotal to organizational survival as the dominance of the independent, single-facility hospital continues to be eroded rapidly (Conrad, et al., 1988; Shortell, 1988).

For the hospital, the expected strategic benefits of this system include: (1) high switching costs incurred by community physicians when they refer their patients to other hospitals; (2) an effective barrier to entry because of capital requirements to invest in computer systems; (3) enhanced patient satisfaction because better services are provided in admission and clinical care; and (4) healthcare service differentiation as a defensive weapon against substitute services.

An extension of the HIS described in case 4 is to connect the hospital's computer to third-party payers' computers. ${ }^{10}$ The incentives for the third-party payers (an important competitive force in the healthcare industry) to connect their computers to the hospital's computer would be to cut

\footnotetext{
10 Medicare has aiready implemented a trial system to facilitate and monitor beneficiary drug use from pharmacies $(\theta . g .$, see Tolchin, M., "System to Track Medicare Drugs," The New York Times, Wednesday, July 13, 1988, p. 1).
} 
down their own staff level by reducing the data entry work, to reduce error rates in data entry by eliminating certain steps in input procedures, to constantly monitor the patient throughout the stay to see if a cost ceiling on the stay is reached, to speed up the information flow, and most importantly to put themselves in a favorable position when negotiating with the hospital. In order to provide these incentives to third-party payers, all the charges related to the patient's stay in the hospital should be integrated as they occur, which requires the integration of various transaction processing systems within the HIS.

Networking with third-party payers' computers provides enormous strategic benefits for the hospital. First of all, the hospital can speed up the payment process by receiving progress payments (i.e., payments of costs incurred to date before the patient is discharged) from the thirdparty payer, thereby improving its financial situation. Also, the hospital can effectively handle a pre-admission review process. Currently, when a patient is admitted, the hospital admission clerks determine if the admission diagnosis is covered in the patient's policy, in order to ensure that third-party payers will pay. ${ }^{11}$ This could be done through the use of the hospital's computer networked with the third-party payer's computers.

The network system connecting the hospital's computer to community physicians' and thirdparty payers' computers is not a highly sophisticated decision support system, but simply an application of TPS/IRS that allows compatibility with a competitive force (Proposition 3). In order to achieve the strategic benefits from the system, however, it would be necessary for the hospital to integrate medical records, patient billing, thirdparty payers, laboratory, and referring physicians' subsystems (Proposition 2). Meanwhile, this integration is feasible only when the hospital medical staff cooperates by participating in the system development, by providing the necessary data, and by using the system (Proposition 1).

\section{Implications and Conclusions}

This article has examined the issue of IST as a competitive weapon in the healthcare industry.

\footnotetext{
11 At the present time this process is both costly and time consuming to payers and providers alike.
}

The preceding discussion identified many of the successful IST applications as having had their origins not in sophisticated DSS, but in already existing tactical systems. As these systems are developed, integration becomes a critical factor in IST success.

Although the hospital industry has made rapid progress in IST development, the systems currently available tend to be quite isolated and independent. HIS development has been driven in large part by environmental influences, and hence, there has been no coherent policy for IST application in most organizations. The problems of isolation are exacerbated in the healthcare industry due to the political conflict inherent between administrators and clinicians. Integration of independent HIS must encompass more than a mere merger of the myriad of administrative systems, due to the unique characteristics of the shared governance structure in hospitals.

Many of the arguments developed in this article are also appropriate for organizations in general, since the propositions are developed from the analysis of field experiences in the healthcare industry as well as other industry examples that have appeared in the literature. Further, political conflict among various groups is not uncommon in other organizations.

Implications for future research can be derived from the above arguments. First, empirical investigations that examine the propositions developed in this article are needed. While empirical evidence in support of the propositions is sought from widely cited cases of successful IST applications, more systematic investigations-which include both cross sectional study and detailed field examinations-are also clearly needed. Second, future research is necessary to investigate the role of information in strategy development and organizational adaptation in the healthcare sector. Although the research in this area has recognized the importance of physicians in the development of organizational strategies, it has ignored the role of physicians in helping to develop the integrated HIS necessary to operationalize these plans. Third, this article has argued that political barriers between physicians and administrators may be a significant problem hindering the integration of existing isolated systems. Several research questions can be raised to address this issue: (1) How can healthcare organizations handle the conflict between 
physicians and administrators to achieve HIS integration? (2) Can HIS be used in any way to mitigate the conflict between the two parties? and (3) What implications does the political barrier have on organizational power structures and integrating physician information into the HIS?

Some implications for practicing managers can also be derived from the above analyses. First, the complexity of the technical and political environment around the integrated information systems suggests that planning is vital to success. In information systems planning, it is considered important that the organization's strategic plan be the basis for the MIS strategic plan (Davis and Olson, 1985). Second, this article points out that integration of the existing isolated systems may not be an easy task because it cuts across political boundaries. The integrated system may change the balance of power among business units as its shape is influenced largely by organizational politics. Often these problems can be solved only when top management shows clear support for the overall information systems plan (Martin, 1983). Thus, top management must provide sufficient support to arbitrate political issues surrounding the integration of the independent systems. Third, user participation, including physicians, in the development and applications of IST for strategic advantages is vital to success. Ives and Olson (1984) summarize that user involvement in MIS improves the chance of MIS success by providing more accurate user information needs, by improving user understanding of the system, by leading to system ownership by users, and by committing users to the system. Thus, practicing managers should try to include end users in MIS projects to enhance the chance of MIS success.

\section{Acknowledgements}

The authors would like to thank both the Department of Accounting \& MIS and the College of Business Administration at Penn State for financial support of this project while they were both on the faculty at Penn State. Critical insight for this paper was received from Barry Cushing, Mark Dirsmith, Uma Umanath, members of the Penn State Healthcare Roundtable, and participants in the MIS research seminar series at Penn State.

\section{References}

Altman, S. and Rodwin, M. "Halfway Competitive Markets and Ineffective Regulation: The American Healthcare System," Journal of Health Politics, Policy and Law (13:2), 1988, pp. 323-340.

Bakos, Y. and Treacy, M. "Information Technology and Corporate Strategy: A Research Perspective," MIS Quarterly (10:2), June 1986, pp. 107-119.

Barrett, S. "Strategic Alternatives and Interorganizational System Implementations: An Overview," Journal of Management Information System (3:3), 1986-87, pp. 5-16.

Barrett, S. and Konsynski, B. "Inter-organization Information Sharing Systems," MIS Quarterly, Special issue, December 1982, pp. 93-104.

Benjamin, R. and Scott Morton, M. "Information Technology, Integration, and Organizational Change," Interfaces (18:3), May-June 1988, pp. 86-98.

Benjamin, R., Rockart, J., Scott Morton, M. and Wyman, J. "Information Technology: A Strategic Opportunity," Sloan Management Review (25:3), 1984, pp. 3-10.

Burnstine, D. BIAIT: An Emerging Management Engineering Discipline, working paper, BIAIT Int., Petersburg, NY, 1980.

Cale, E. and Curley, K. "Measuring Implementation Outcome: Beyond Success and Failure," Information \& Management (13:5), 1987, pp. 245-253.

Cash, J. and Konsynski, B. "IS Redraws Competitive Boundaries," Harvard Business Review (63:2), 1985, pp. 134-142.

Conrad, D., Mick, S., Madden, C. and Hoare, C. "Vertical Structures and Control in Healthcare Markets: A Conceptual Framework and Empirical Review," Medical Care Review (45:1), 1988, pp. 49-100.

Cook, K., Shortell, S., Conrad, D. and Morrisey, M. "A Theory of Organizational Response to Regulation: The Case of Hospitals," Academy of Management Review (8:2), 1983, pp. 193-205.

Davis, G. and Olson, M. Management Information Systems: Conceputal Foundations, Structure, and Development, McGraw-Hill, New York, NY, 1985.

Dock, T. and Wetherbe, J. Computer Information Systems for Business, West Publishing, St. Paul, MN, 1988. 
Eastaugh, S. Financing Health Care: Economic Efficiency and Equity, Auburn House, Dover, MA, 1987.

Enthoven, A. "Managed Competition of Alternative Delivery Systems," Journal of Health Politics, Policy and Law (13:2), 1988, pp. 305-321.

Friedson, E. "The Reorganization of the Medical Profession," Medical Care Review (41:1), 1985, pp. 11-36.

Harrell, G. and Fors, M. "Planning Evolution in Hospital Management," Healthcare Management Review (12:1), 1987, pp. 9-22.

Havinghurst, $C$. "The Changing Locus of Decision Making in the Health Care Sector," Journal of Health, Politics, Policy and Law (11:4), 1986, pp. 697-735.

Hoffman, M. "Systems Management: Strategies to Increase Effectiveness," Healthcare Financial Management, June 1986, pp. 44-48.

Ives, B. and Learmonth, G. "The Information System as a Competitive Weapon," Communications of the ACM (27:12), 1984, pp. 1193-1201.

Ives, B. and Olson, M. "User Involvement and MIS Success: A Review of Research," Management Science (30:5), May 1984, pp. 586-603.

Johnston, H. and Vitale, M. "Creating Competitive Advantage with Interorganizational Information Systems," MIS Quarterly (12:2), June 1988, pp. 153-166.

Kaluzny, A., Alexander, J., Hurley, R. and Galloway, R. "Competition and Survival of Health Service Organizations: A Population Ecology Approach," International Journal of Health Planning and Management (2:1), 1987, pp. 3-14.

Keen, P.G.W. "Information Systems and Organizational Change," Communications of the ACM (24:1), 1981, pp. 24-33.

Kimberly, J. and Zajac, E. "Strategic Adaptation in Healthcare Organizations: Implications for Theory and Research," Medical Care Review (42:2), 1985, pp. 267-302.

Lemon, R. and Crudele, J. "Systems Integration: Tying It All Together," Healthcare Financial Management, June 1987, pp. 46-53.

Lemon, R. and Meier, J. "Transition Strategies: Moving Systems from Old to New," Healthcare Financial Management, July 1987, pp. 56-65.
Malvey, M. Simple Systems, Complex Environments, Sage, Beverly Hills, CA, 1981.

Markus, M.L. and Bjdrn-Andersen, N. "Power over Users: Its Exercise by System Professionals," Communications of the ACM (30:6), 1987, pp. 498-504.

Martin, J. Managing the Data-base Environment, Prentice-Hall, Englewood, Cliffs, NJ, 1983.

McFarlan, F.W. and McKenney, J.L. Corporate Information Systems Management: The Issues Facing Senior Executives, Irwin, Homewood, IL, 1983.

Mintzberg, H. The Structuring of Organizations, Prentice-Hall, Englewood Cliffs, NJ, 1979.

Ohmae, K. The Mind of the Strategist, McGrawHill, New York, NY, 1982.

Pettigrew, A. "Information Control as a Power Resource," Sociology (6:2), 1972, pp. 187-204.

Porter, M. "How Competitive Forces Shape Strategy," Harvard Business Review, MarchApril 1979, pp. 137-145.

Porter, M. Competitive Strategy, Free Press, New York, NY, 1980.

Porter, M. Competitive Advantage, Free Press, New York, NY, 1985.

Reynolds, J. "Using DRGs for Competitive Positioning and Practical Business Planning," Healthcare Management Review (11:3), 1986, pp. 37-55.

Roemer, M. and Shain, M. Hospital Utilization Under Insurance, Hospital Monograph Series, No. 6, American Hospital Association, Chicago, IL, 1959.

Senn, J. Information Systems in Management, Wadsworth, Belmont, CA, 1987.

Shortell, S. "The Evolution of Hospital Systems: Unfulfilled Promises and Self-fulfilling Prophesies," Medical Care Review (45:2), 1988, pp. 177-214.

Shortell, S., Morrison, E. and Robbins, S. "Strategy Making in Healthcare Organizations: A Framework and Agenda for Research," Medical Care Review (42:2), 1985, pp. 219-266.

Starr, P. Transformation of America Medicine, Basic Books, New York, NY, 1982.

Stone, D. "Physicians as Gatekeepers," Public Policy (27:2), 1979, pp. 227-254.

Treacy, M. Toward a Cumulative Tradition of Research on Information Technology as a Strategic Business Factor, CISR working paper 134, Massachusetts Institute of Technology, Cambridge, MA, 1986. 


\section{About the Authors}

K. Kyu Kim is an assistant professor of MIS at In-ha University in Inchon, Korea. He received his B.A. in business administration from Seoul National University and both an M.B.A. and Ph.D. degree from the University of Utah. His current research interests are in MIS organizational structure, MIS implementation, MIS effectiveness, and strategic use of MIS. He has published in The Accounting Review, Information and Management, and Journal of Information Systems.

Jeffrey E. Michelman is an assistant professor of accounting at the University of North Florida in Jacksonville, Florida. He received his B.S. degree from the University of Delaware in accounting and economics, his M.H.A. degree from Washington University in St. Louis, and both an M.B.A. and Ph.D. degree in business from the University of Wisconsin-Madison. He has published several articles on end stage renal disease in the American Journal of Kidney Diseases. His current research interests include the role of accounting information in healthcare decisionmaking processes and the strategic use of information systems in the healthcare setting. 